\title{
Drug Use, Personality and Partner Violence: A Model of Separate, Additive, Contributions in an Active Drug User Sample
} \author{
Steve Reise ${ }^{1}$ and Peter Bentler ${ }^{1}$ \\ ${ }^{I}$ Department of Psychology, University of California, Los Angeles, USA \\ ${ }^{2}$ Department of Psychology, California State University, Long Beach, USA \\ ${ }^{3}$ Center for Behavioral Research and Services, California State University, Long Beach, USA
}

Adi Jaffe ${ }^{*}, 1$, William C. Pedersen ${ }^{2}$, Dennis G. Fisher ${ }^{3}$, Grace L. Reynolds ${ }^{3}$, Scott L. Hershberger ${ }^{2}$,

\begin{abstract}
Drug use is considered a main contributing factor to crime and violence. This research examined the evidence regarding the relationship between drug abuse and the occurrence of intimate partner violence. Current drug using men were assessed on aggression related personality variables, their drug use, and the occurrence of violence in their close relationships. A latent aggression factor and recent amphetamine use were the only variables found to be significantly associated with violence. No other drug use variables were found to be associated with violence by the participant and the overall drug use factor was not found to be associated with violence or aggressive personality. The widely accepted notion that increased substance use directly leads to increases in violent behavior was only partially supported, at least within this drug using population. The assessment of aggressive personality, rather than of drug use, is suggested for correctional as well as clinical settings in which drug users are prevalent when determining susceptibility to violence.
\end{abstract}

Keywords: Substance abuse, intimate partner violence, violence, aggression, rumination, structural equation modeling.

\section{DRUG USE, PERSONALITY AND PARTNER} VIOLENCE:

A Model of Separate, Additive, Contributions in an Active Drug User Sample

Drug use and abuse has undoubtedly become one of the prevailing social ills of our modern society. It is currently estimated that over 110 million people in the United States (U.S.) over the age of 12 years have used an illicit substance either in their lifetime, the past year, or the past month [SAMHSA, 1]. Even when marijuana use is excluded from the calculations, the numbers are still staggering, with estimates above 71 million people. In fact, although the majority of people sent to prison in the U.S. are nonviolent drug offenders, drug control policies in the U.S. have been seen as the main cause for the quadrupling of the national prison population since 1980 [2]. Indeed, the establishment of a number of federal agencies (e.g., National Institute for Alcoholism and Alcohol Abuse and National Institute on Drug Abuse) dealing with alcohol and drug abuse was justified based on the assumed link between drug use and crime, especially violent crime [3].

The use of drugs has long been associated with several behaviors and conditions that are seen as disruptive to the normal functioning of individuals and society at large. These include, but are not limited to, increases in disease [e.g., HIV and Hepatitis; 4] and sexual risk behaviors [5, 6], temporary physical impairment leading to driving accidents [7],

*Address correspondence to this author at the Department Of Psychology, University of California, 1285 Franz Hall, Box 951563, Los Angeles, CA 90095-1563, USA; E-mail: adi@ucla.edu increases in frequency of partner violence [8], work impairment, as well as substantial legal and financial burdens on both persons and society [9].

The association between alcohol-, drug-use, and intimate partner violence (IPV) has seen especially strong support in the literature [10-16]. Still, while the association seems robust, a careful examination of this literature equivocates the drugsviolence connection somewhat leaving alcohol-related problems, and not simple alcohol consumption, as the most reliably associated with IPV. In fact, many of the above examinations are lacking in the breadth of their assessment of violence-relevant personality variables of the perpetrator, or victim, of IPV. Furthermore, the meta-analysis performed by Moore et al. (2008) found the strongest effect size of drug use on aggression within samples that did not specifically target substance users. This, along with the acknowledgment that unaccounted for third variables that, which may be related to both aggression and substance use (e.g., impulsivity), suggests the that within a drug using sample, relatively weak effects of drug use on violence may be expected.

Even within the general aggression and violence literature, drug-use associated increases in violence have often been shown to be mediated by person-specific characteristics (e.g., preexisting psychosis, Post Traumatic Stress Disorder, early patterns of aggressive behavior) and contextual (e.g., harsh discipline, lack of parental supervision, relationship to target, location) factors [17-19]. Numerous researchers have suggested that while alcoholism and criminality do tend to co-occur, there is no evidence that alcoholic criminals commit more serious, violent crimes than nonalcoholic criminals or that a causal interpretation is warranted [20, 21]. Anglin [22], concluded that even for alcohol, for which a strong empirical correlation with 
crime has been established, the preponderance of evidence indicates no causal relationship for the majority of alcohol users and that this relationship would be best approached by more complex theoretical models.

Indeed, while it is estimated that more than $61 \%$ of the U.S. population over the age of 18 engaged in alcohol consumption in 2006, with more than $42 \%$ consuming more than five drinks on at least one day [23], less than $1 \%$ of the general population was involved in violent crime of any kind during that same year [24]. These findings seem to indicate that more than mere exposure to alcohol, or drugs, is at play in the occurrence of violence. The goal of this work is to elucidate what, other than alcohol and drug use, may contribute to the occurrence of violence among drug users.

\section{Personality Variables Related to Violence}

It should come as no surprise that individuals higher in trait aggression have been found to aggress, physically and/or verbally, more often than those lower on trait aggression. This has been found to be true in juvenile offenders [25], the mentally ill [26], Vietnam veterans [27], and in a host of nonclinical samples [28-30], for behaviors ranging from shock delivery, to driving, violence-related hockey penalty minutes, bullying and fighting. Nevertheless, the use of aggression measures as proxies for violent behavior in many drug useviolence studies has been called into question due to its oversimplification of the transition from aggressive trait to overt violence [31]. This is due, in part, to the fact that a number of variables aside from trait aggression and anger have been shown to be important in predicting the actual occurrence of violence including educational attainment [32], self-esteem, attitudes about violence, and interpersonal provocation [33], as well as rumination [34].

While perhaps not exhaustive, research using a number of the above-mentioned variables has still shown an association, albeit an often-reduced one, between IPV and drug and alcohol use severity $[8,35]$. While the use severity of specific drugs did not prove to be a significant predictor of actual physical abuse in the Stuart et al. sample, overall drug use severity in male perpetrators did significantly predict higher physical abuse. These equivocal findings leave some doubt regarding the veracity of the claim that illicit drugs bring about an increase in violent behavior.

\section{The Present Research}

The purpose of the present study was to assess the relationship between illicit-drug use severity (i.e., drug type, use frequency, length of use, and method of use) and intimate partner violence in a sample of current drug using men. The models presented in this paper will include a broad assessment of trait characteristics related to violence as well as numerous measures of drug use. We hypothesize that aggressive personality, rather than drug use, will be most associated with increases in violent behavior and that drug use, regardless of its specific indicator would, if at all, be weakly associated with violent behavior in this sample.

\section{METHOD}

\section{Participants}

Participants were recruited through two HIV prevention and/or HIV/STD testing programs operated by the Center for
Behavioral Research and Services (CBRS) at California State University, Long Beach (CSULB). CBRS operates a food bank as well as a prevention center central to several neighborhoods with a high prevalence of drug use. The Intervention for HIV Negative and HIV Positive Drug Users (IHNHP) used a three-session intervention with current, outof-treatment drug users, focused on risk reduction goals and social support for HIV risk reduction. This program was funded by the City of Long Beach. The Multiple Morbidities Testing Program (MMTP) provided HIV, STD, and hepatitis testing for a variety of behavioral risk groups. Eligibility requirements for the both programs resulted in enrollees who were current drug users (i.e., within the past 30 days) at the time of enrollment and at least 18 years of age.

\section{Materials}

After signing an informed consent form that had been approved by the CSULB Institutional Review Board (IRB), participants underwent an extended structured interview which included the administration of the following instruments:

The Revised Conflict Tactics Scale (CTS-2) is a 78-item questionnaire instrument created to measure the extent to which different conflict resolution tactics, including psychological and physical violence, have been used by couples during conflict $[8,36]$. The CTS2 measures five such conflict resolution tactics: Negotiation, Psychological Aggression, Physical Assault, Injury, and Sexual Coercion. The conflict resolution tactic of import for the current investigation was participant-inflicted Physical Assault (i.e., the DV, referred to as Violence), made up of 12 questions addressing aggressive behavior initiated by the participant (e.g., "I slapped my partner").

The Risk Behavior Assessment (RBA) was developed by the National Institute on Drug Abuse (NIDA) in collaboration with the Cooperative Agreement for AIDS Community-Based Outreach/Intervention Research program (CA) grantees. Aimed at assessing risk for HIV infection, the RBA is a structured 20-45 minute interview covering demographic, drug use, incarceration, and sexual risk behaviors [37-40]. Drug use question included lifetime use (Yes/No), age of first use, use frequency, and use of injection for numerous substances including alcohol, marijuana, amphetamines, cocaine, crack cocaine, heroin, and more. All counselors administering the RBA at CBRS undergo training sessions, including three observations and three supervised administrations.

The Aggression Questionnaire [AQ; 41] is a multidimensional instrument used to assess an individual's tendency towards aggressive responding. The Aggression Questionnaire (AQ) is an updated version of the BussDurkee Hostility Inventory [42]. The AQ uses a forced choice Likert scale with responses to items (e.g., "If somebody hits me, I hit back.") ranging from 1 (Not at all like me") to 5 ("Completely like me").

The Dissipation-Rumination scale [DR; 43] is used to assess trait rumination, or one's tendency to harbor or even enhance feelings of vengeance with the passage of time with items such as "When I am outraged, the more I think about it, the angrier I become", "I can remember very well the last time I was insulted", and "Sometimes I can't sleep because 
of a wrongdone to me", [43]. The scale is made up of 15 items found to load highly on the single expected factor, as well as 5 items with loading coefficients close to zero, which are used as control or distracter items to avoid response-set effects [43].

The Novaco Anger Scale and Provocation Inventory [NAS/PI; 44] is a two-part, self-report questionnaire consisting of 85 questions. The scale is meant to measure anger disposition, assessing "trait-like aspects of anger responding or anger response readiness" [44], and includes items such as "My temper is quick and hot" (NAS; possible answers are "Always true", "Sometimes true", and "Never True") and "Someone makes fun of the clothes you are wearing" (PI; possible answers are "Very angry", "Fairly angry", "A little angry", and "Not at all angry"). While the terminology used by the creators of the NAS is different from that used by the AQ [41], it should be pointed out that the Cognitive, Behavioral, and Arousal dimensions of the NAS correspond to the Hostility, Physical Aggression, and Anger subscales of the AQ respectively. The PI provides a separate score from the NAS and is intended to provide an assessment of anger intensity and generality across different provocation instances.

\section{Procedure}

Upon arrival at the center, participants were asked to complete an initial information sheet which included their name, address, and date of birth. This information was then used to locate their client identification number which was used to track their progress through the program. Clients who were due for interviews (i.e., had not been interviewed in 3 months) were then administered the CSULB Institutional Review Board (IRB) approved consent form, which they signed, and were taken to an interview room where administration of the above instruments took place. Instruments were administered in the order in which they were presented earlier, and a number of instruments unrelated to the present study were also completed during the interview. Trained CBRS staff administered all instruments, and participants were given $\$ 10$ in McDonalds vouchers upon completion of the interview as an additional incentive for participation. All subjects were then reminded of the date of their next interview and dismissed.

\section{Analysis}

Following administration, instruments were coded, entered and verified by CBRS staff using data entry programs such as NOVA Data Entry, and Viking Data Entry (VDE). Data were then stored on the secure CBRS server. Initial data compilation and analysis was completed using SAS-STAT (9.1) software. Structural models were tested for fit using structural equation modeling software (EQS 6.1).

Missing data were handled using Maximum Likelihood (ML) estimation methods built into EQS in order to maximize usage of available data points ${ }^{1}$. Goodness-of-fit of the models was assessed with the maximum-likelihood $\chi^{2}$ statistic, the Comparative Fit Index (CFI) and the root mean

\footnotetext{
${ }^{1}$ This method also provides estimates of population means of variables. As these are not relevant to our hypotheses, they are not presented in results or figures.
}

squared error of approximation (RMSEA) [45-47]. The CFI ranges from 0 to 1 and reflects the improvement in fit of a hypothesized model over a model of complete independence among the measured variables [45]. Values approaching .95 or greater are desirable for the CFI. The RMSEA is a measure of fit per degrees of freedom, controlling for sample size; values less than .06 indicate a relatively good fit [47]. Suggestions for modifications were obtained from the LaGrange Multiplier (LM) test [45].

\section{RESULTS}

\section{Demographics}

The majority of the 126 male participants were Black $(80,63.5 \%)$, with Hispanic $(10,7.9 \%)$, and White (32, $25.4 \%$ ) participants making up the other two wellrepresented racial groups. All available cases were used in the computation of all means presented ${ }^{2}$. Participants' age ranged between 21.84 years and 73.78 years with a mean of 44.47 years $(S D=9.70)$. More than a third of participants $(47,37.3 \%)$ completed high school or equivalent (i.e., GED), with slightly smaller groups having some college, or less than high-school education. A small number of participants reported having completed a college degree $(14,11.1 \%)$. Most participants reported their current residence as either their own or someone else's house or apartment (84, 47.4\%). Still, a considerable portion of this sample reported living in transient housing, such as a hotel, boarding/halfway house, or a shelter, and 19 participants (10.8\%) reported living on the streets. The mean number of lifetime arrests in this sample was $12.11(S D=49.02)$ with an average of 2.51 years spent in jail/prison $(S D=4.21)$.

\section{Drug Use}

The average number of years of alcohol $(M=29.74, S D$ $=10.78)$, crack $(M=13.36, S D=10.09)$, and amphetamine $(M=8.37, S D=11.97)$ consumption were reported along with average past month use of each of these drugs (Table 1). Crack was the most frequently used illicit drug in this sample $(M=6.31$ days, $S D=9.19)$, and a substantial minority of participants reported previously having injected drugs $(46,36.51 \%)$. An examination of the correlation matrix (Table 2) reveals a pattern of associations between use of specific drugs (e.g., alcohol and crack).

\section{Aggression and Violence}

Participants' average score on the physical assault portion of the CTS-2 was $1.53(S D=3.09)$, somewhat higher than the CTS-2's male college student norm sample mean of $1.08(S D=1.80)$. It should also be noted that these norm comparable scores include only participants who endorsed at least one of the scale items, while in our sample 81 participants $(44.51 \%)$ reported no occurrences of violence in the past 12 months. Mean scores on the four aggression questionnaires ranged from 1.90 (NAS) to 2.47 (PI) and did not differ significantly from reported norms. Strong correlations were found among all aggression instruments (Table 2), including the Dissipation Rumination scale.

\footnotetext{
${ }^{2}$ All variables contained less than $1.1 \%$ of cases missing except for recent injection ( $5 \%$ missing).
} 
Table 1. Demographics \& Drug Use

\begin{tabular}{|c|c|c|}
\hline & Demographics & $N(\%)$ \\
\hline \multirow{4}{*}{ Race } & Black & $80(63.5)$ \\
\hline & White & $32(25.4)$ \\
\hline & Hispanic & $10(7.9)$ \\
\hline & Other & $4(3.2)$ \\
\hline \multirow{2}{*}{ Employment Status } & Working/School/Military/Homemaker & $24(19.0)$ \\
\hline & Unemployed/retired/disabled & $102(81.0)$ \\
\hline \multirow{4}{*}{ Education } & Less than High-School & $27(21.4)$ \\
\hline & High-School or GED & $47(37.3)$ \\
\hline & Some college/trade school & $38(30.2)$ \\
\hline & College graduate & $14(11.1)$ \\
\hline \multirow{4}{*}{ Housing } & Own/someone else's house/apt & $67(53.2)$ \\
\hline & Hotel/Boarding house/shelter & $40(31.8)$ \\
\hline & On the streets & $16(12.7)$ \\
\hline & Other & $3(2.3)$ \\
\hline & & Mean $(S D)$ \\
\hline Age & & $44.47(9.70)$ \\
\hline Lifetime arrests & & $15.08(57.69)$ \\
\hline Years in Jail/Prison & & $3.10(4.65)$ \\
\hline Drug Use & & Mean $(S D)$ \\
\hline \multirow{2}{*}{ Alcohol } & Days of use in last 30 days (Alcohol 30) & $12.42(11.28)$ \\
\hline & $\%$ of lifetime using (Alcohol \%) & $65.04 \%(14.40)$ \\
\hline \multirow{2}{*}{ Crack } & Days of use in last 30 days (Crack 30 ) & $6.31(9.19)$ \\
\hline & $\%$ of lifetime using (Crack \%) & $28.97 \%(21.11)$ \\
\hline \multirow{2}{*}{ Amphetamines } & Days of use in last 30 days (Amph 30) & $.94(3.65)$ \\
\hline & $\%$ of lifetime using (Amph \%) & $18.24 \%(24.71)$ \\
\hline \multirow{2}{*}{ Injection Drug Use } & Days in last 30 days (IDU 30) & $3.70(16.25)$ \\
\hline & $\%$ of lifetime injecting (IDU \%) & $14.95 \%(23.11)$ \\
\hline
\end{tabular}

\section{Structural Equation Models}

The structural model (Fig. 1) was constructed in a manner consistent with current theory on the relationship between drug use, aggression and violence. As such, it contained an aggression factor as well as an overall drug-use factor, both of which were hypothesized to be associated with violence and set to covary. Estimation was done using normal theory maximum likelihood, and due to significant deviations from normality in variable distribution indicated by Mardia's standardized multivariate kurtosis measure $\left(\mathrm{g}_{2,15}\right.$ $=19.45$ ), robust statistics were used in model evaluation.

This model provided excellent fit, $\left(\chi^{2}(52, N=126)=\right.$ 57.43, $p>.05)$ with $\mathrm{CFI}=.98$ and $\mathrm{RMSEA}=.029$ (Standardized parameters for the model are given in Fig. 1). However, while the aggression instruments provided good loadings onto a single factor, the same was not true of all drug use factors. Two of the eight drug use variables used (i.e., recent amphetamine use and recent injection) failed to load significantly on the overall drug use factor. Consequently, these two variables were identified as independent from the overall drug use factor. This change resulted in the eventual removal of the recent injection variable from the model for parsimony. In addition, the drug use factor itself was not found to correlate significantly with the aggression factor, nor did it add significantly to the variability explained in CTS- 2 scores. For these reasons, the model was adjusted by removing all non-significant paths and allowing the recent-use-of-amphetamine variable to be independently associated with CTS-2 scores. This final, parsimonious, model seen in Fig. (2) provided even better fit than the initial model $\left(\chi^{2}(53, N=126)=55.82, p>.05\right.$, CFI $=.99$, RMSEA $=.025)$. As can be seen in the figure, there is a strong association between aggressive trait features and the occurrence of violence. Furthermore, contrary to our initial hypothesis, a significant relationship was found between the recent use of methamphetamine, the only drug-related 
Table 2. Correlations Between SEM Model Variables

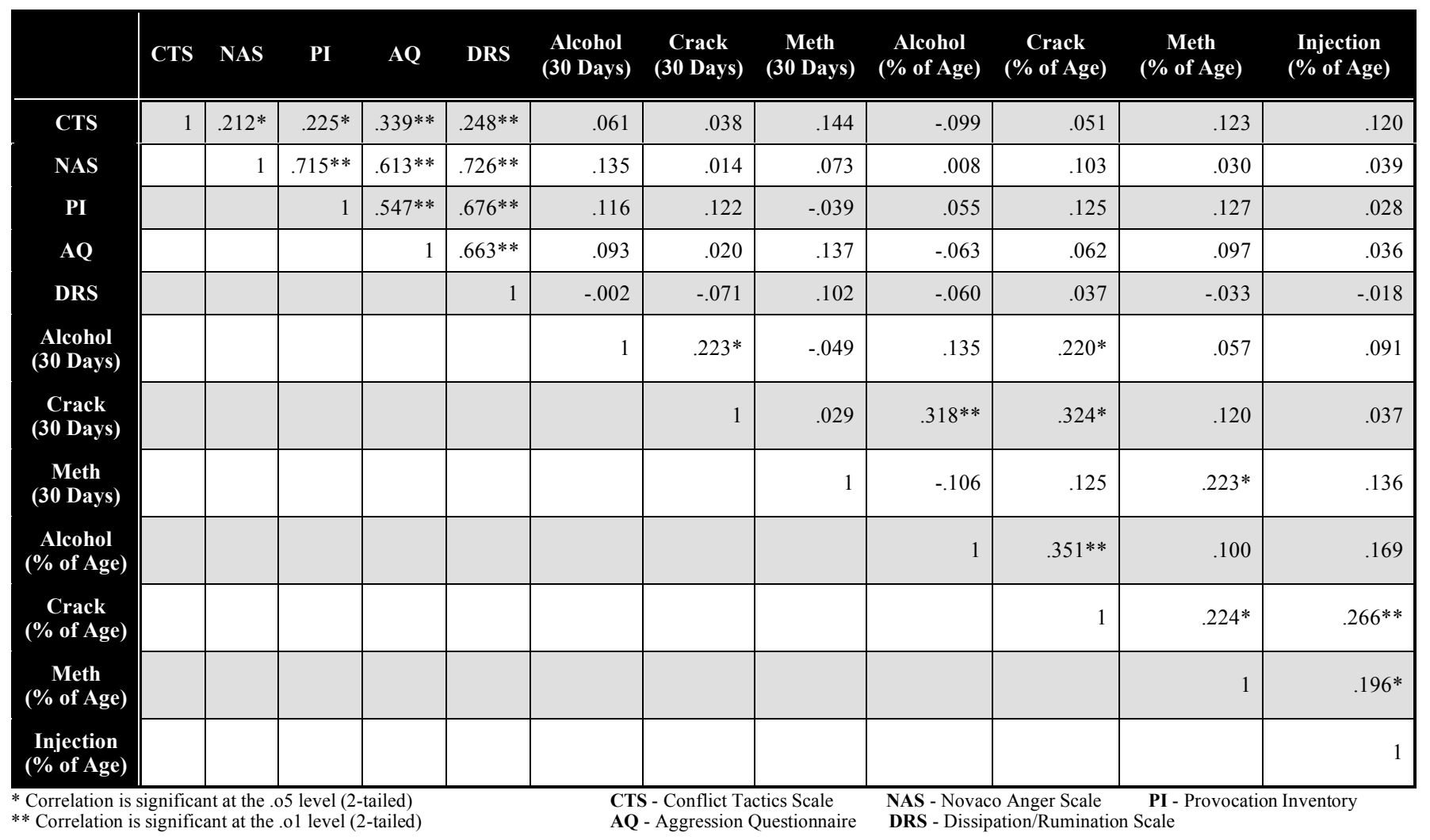

variable that did not load well onto the general drug use factor, and violence.

\section{DISCUSSION}

The present research evaluated a model of the relationship between recent and lifetime drug use and aggressive personality in the prediction of past-year IPV within a drug using population. By assessing the frequency of natural-setting (i.e., rather than laboratory facilitated) violent behaviors instead of simply assigning participants to a violent or nonviolent group, it was expected that finer details of the associations could be revealed. Moreover, a distinct context for violence (i.e., intimate partner violence) was used in order to limit contextual effects.

Multiple, distinct instruments were used to assess aggressive personality in order to better understand the relationship between trait aggression and IPV. This method resulted in a well-defined aggressive-personality latent factor showing strong relationships among the four measures. This finding is noteworthy in that it extends support for the notion that trait rumination is closely related to other more common personality variables contributing to aggressive behavior. In fact, rumination loaded onto the aggressive-personality construct so well, it would seem it is as important in the process as trait anger and trait aggression. Given this and other findings regarding the effects of rumination on maladaptive behavior (e.g., depression and aggression), it is likely that high trait rumination in itself may be a marker for, or itself is, a form of maladaptation. Future research could help elucidate this concept further. The strong association between the aggressive-personality latent factor and the occurrence of past year IPV adds further support to an already robust literature regarding the relationship between aggression related tendencies and explicit behavior.

In addition to the assessment of aggression-related personality variables, multiple indicators of drug use including lifetime, as well as recent, use of alcohol, crack, and amphetamines were included in the model in order to best assess their relationship to violence. Of these, recent amphetamine use was found to be the only drug related variable that was significantly associated with the occurrence of partner violence. Interestingly, recent amphetamine use was found not to load significantly onto the overall drug use factor, but instead to be independently associated with increased violence. The notion that the recent use of amphetamines is somehow different from all other drug-usevariables used in this study is one of great interest, and should be explored further. While the physiological effects of cocaine and methamphetamine are similar [48], it seems that there may be something unique about the recent use of amphetamines that is unrelated to an overall drug-using personality.

These results support the notion that aggressive tendencies apart from, and ostensibly present prior to, drug use may be driving the apparent drug-violence connection, at least within this population. In light of these findings, it would seem that the appraisal of dangerousness in situations that involve IPV among drug using individuals (e.g., probation offices, drug treatment programs, batterer education programs) would benefit more from an extensive assessment of aggression related personality variables such as those used here, rather than by assessing the severity of individual drug use. Our results indicate that the use of amphetamines may be an exception to this rule. 


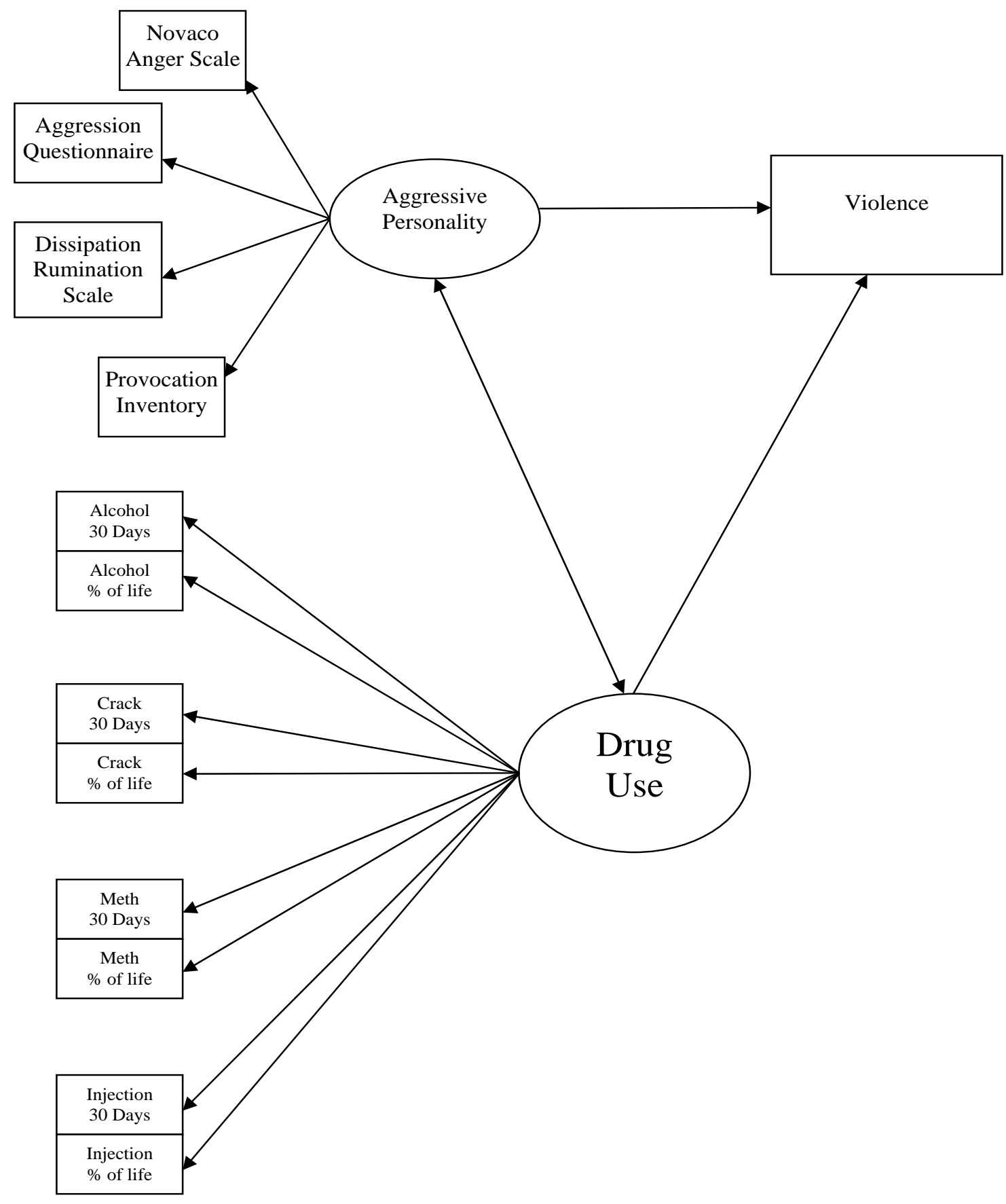

Fig. (1). The initial theoretical model showing separate aggression and drug use factors that are both associated with the occurrence of violence, and are correlated.

Interestingly, the construct of trait-rumination was so highly associated with other aggression-related constructs that the authors feel confident in recommending that its assessment be incorporated into such contexts as well. The assessment of rumination may be less face-valid than that of anger and aggression and may therefore provide more honest responses that are less affected by social desirability biases.

The present research suffers from a number of limitations common to most studies examining drug use related effects. The absence of a drug-free control group limits the generalizability of findings, though, as the goal of the current research was to specifically examine findings within this population (as occurrence of violence is often thought to occur mostly within it) the significance of this limitation is relatively small. Of further importance to findings' generalizability are issues related to sample representativeness; the present sample's relatively high incarceration rates, imprisonment duration, and unemployment are likely to restrict the results to a relatively narrow proportion of the general population. A high prevalence of Antisocial Personality Disorder (ASPD), as well as other mental health issues has been previously 


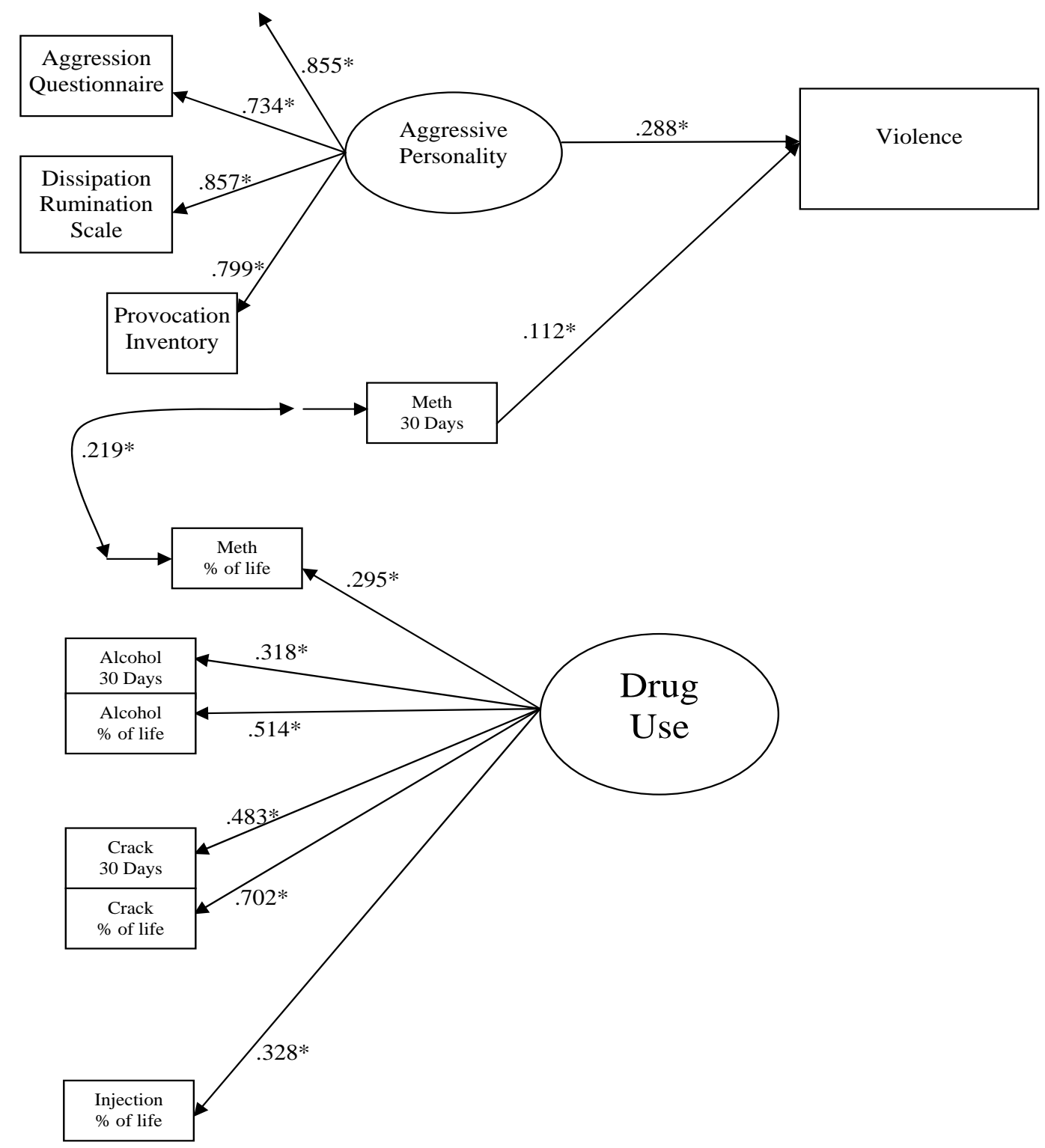

Fig. (2). The final model, showing the absence of any correlation between the drug use factor and aggressive personality or the occurrence of violence. While the recent use of amphetamines did not load well onto the overall drug use factor, it was found to be correlated both with the lifetime use of amphetamine and with the occurrence of past year partner violence.

demonstrated in the literature and should be taken into account when considering the present findings. The collection of self-report data rather than direct observation of both drug use and violent events carries with it the common reliability issues plaguing subjective reporting. These include memory effects as well as selective reporting. We used instruments with well-studied psychometric properties to maximize the reliability, and validity, of our assessment of actual drug use. While experimental manipulations can and should be carried out, these can be especially dangerous within this population. Lastly, the lack of knowledge regarding the temporal relationship between drug use and the occurrence of violence limits these findings.

Present findings reveal limited support to the notion that drug use leads to, or is distinctly associated with, increased partner violence, at least when considered within a drug using population. In fact, general drug use was found not to be associated with intimate partner violence in the past 12 months. It should be noted that even given the relatively comprehensive present examination, only $9.8 \%$ of variability in past year IPV was explained in the final model. While the reliability of self-report may have an effect on this estimate, the present analysis undoubtedly reveals that major contributing factors to violent behavior are still absent from the model and need to be examined. Recent work regarding general neurobiological differences between drug users and non-users may well help in further elucidating some of the yet unincorporated contributing factors to the drugs-violence relationship. The present results strongly suggest that drug use per se is not the cause for many of the expressions of anger and aggression in our society, though it may indeed be related to factors that are. 


\section{ACKNOWLEDGEMENTS}

This research was supported in part by National Instituted of Drug Abuse grant DA 01070-33, contract \#28569 from the City of Long Beach Department of Health and Human Services and contract \#H700939 from the County of Los Angeles Office of AIDS Programs and Policy.

The authors acknowledge Judith A. Stein, Ph.D., for her consultation in analysis and the Center for Behavioral Research and Services staff for helping in data collection and entry.

\section{REFERENCES}

[1] Rockville MD. Substance Abuse and Mental Health Services Administration, National survey on drug use and health. Department of Health and Human Services, Substance abuse and Mental Health Services Administration, Office of Applied Studies 2003.

[2] Grilly DM. Drugs and human behavior. 4th ed. Boston, MA: Allyn and Bacon 2002.

[3] McBride DC. Drugs and violence. In: The drugs-crime connection. Inciardi JA, Ed. Beverly Hills, CA: Sage Publications, Inc 1981; p. 272.

[4] Wells RS, Fisher D, Fenaughty A, et al. A hepatitis A prevalence among injection drug users. Clin Lab Sci 2006; 19: 12-17.

[5] Lejuez CW, Bornovalova MA, Daughters SB, et al. Differences in impulsivity and sexual risk behavior among inner-city crack/cocaine users and heroin users. Drug Alcohol Depend 2005; 77(2): 169-75.

[6] Fisher DG, Reynolds GL, Ware MR, Napper LE. Recreational Viagra use and sexual risk among drug abusing men. Am J Infect Dis 2006; 2 : 107-14.

[7] Siegel RK. Cocaine use and driving behavior. Alcohol Drugs Driving 1987; 3(1): 1-8.

[8] Stuart GL, Temple JR, Follansbee KW, et al. The role of drug use in a conceptual model of intimate partner violence in men and women arrested for domestic violence. Psychol Addict Behav 2008; 22(1): 12-24.

[9] Jung J. Psychology of alcohol and other drugs: A research perspective. Thousand Oaks, CA: Sage Publications Inc 2001.

[10] Coker LA, Smith PH, McKeown RE, King MJ. Frequency and correlates of intimate partner violence by type: Physical, sexual, and psychological battering. Am J Public Health 2000; 90(4): 55359.

[11] Cunradi CB, Caetano R, Schafer J. Alcohol-related problems, drug use, and male intimate partner violence severity among US couples. Alcohol Clin Exp Res 2002; 26(4): 493-500.

[12] Jewkes R. Intimate partner violence: causes and prevention. Lancet 2002; 359: 1423-29.

[13] Silverman JG, Raj A, Mucci LA, et al. Dating violence against adolescent girls and Associated substance use, unhealthy weight control, sexual risk behavior, pregnancy, and suicidality. J Am Med Assoc 2001; 286(5): 572-9.

[14] McCauley J, Kern DE, Kolodner K, et al. The "Battering Syndrome": Prevalence and clinical characteristics of domestic violence in primary care internal medicine practices. Ann Intern Med 1995; 123(10): 737-46.

[15] Leonard EK, Senchak M. Prospective prediction of husband marital aggression within newlywed couples. J Abnorm Psychol 1996; 105: 369-80.

[16] Moore TM, Stuart GL, Meehan JC, et al. Drug abuse and aggression between intimate partners: A meta-analytic review. Clin Psychol Rev 2008; 28(2): 247-74.

[17] Chermack ST, Giancola PR. The relation between alcohol and aggression: An integrated biopsychosocial conceptualization. Clin Psychol Rev 1997; 17(6): 621-49.
[18] National Institute of Justice, Office of Justice Programs 1994.

Giancola PR. Irritability, acute alcohol consumption and aggressive behavior in men and women. Drug Alcohol Depend 2002; 68(3): 263-74.

[20] McCord J. Relationship between alcohol and crime over the life course. In: Kaplan HB, Ed. Drugs, crime, and other deviant adaptations: longitudinal studies. New York: Plenum Press 1995; pp. $129-41$.

[21] Newcomb MD, Harlow LL. Life events and substance use among adolescents: mediating effects of percieved loss of control and meaningless in life. J Pers Soc Psychol. 1986; 51: 564-77.

[22] Anglin MD. Alcohol and criminality. In: Pattison E, Kaufman E, Eds. Encyclopedic Handbook of Alcoholism. New York: Gardner Press 1982; pp. 383-94.

[23] Substance Abuse and Mental Health Services Administration, Results from the 2006 National Survey on Drug Use and Health: National Findings 2007.

[24] Federal Bureau of Investigation. Crime in the United States 2006. 2007; Available from: http://www.fbi.gov/ucr/cius2006/data/table_ 01.html

[25] Ireland JL, Archer J. Association between measures of aggression and bullying among juvenile young offenders. Aggress Behav 2004; 30(1): 29-42.

[26] Wang EW, Diamond PM. Emperically identifying factors related to violence risk in corrections. Behav Sci Law 1999; 17(3): 377-89.

[27] Freeman TW, Roca V. Gun use, attitudes toward violence, and aggression among combat veterans with chronic posttraumatic stress disorder. J Nerv Ment Dis 2001; 189(5): 317-20.

[28] Bushman BJ, Wells GL. Trait aggressiveness and hockey penalties: Predicting hot tempers on the ice. J Appl Psychol 1998; 83(6): 96974.

[29] O'Conner DB, Archer J, Wu FWC. Measuring aggression: Selfreports, partner reports, and response to provoking scenarios. Aggress Behav 2001; 27(2): 79-101.

[30] Giancola PR. Alcohol-related aggression in men and women: The influence of dispositional aggressivity. J Stud Alcohol 2002; 63(6): 696-708.

[31] Parker RN, Auerhahn K. Alcohol, drugs, and violence. Ann Rev Sociol 1998; 24(1): 291-313.

[32] Wagdy L, Gurmeet KD. Predicting violence among forensiccorrectional populations: the past 2 decades of advancements and future endeavors. J Interpers Violence 2005; 20(2): 188-94.

[33] Anderson CA, Bushman BJ. Human aggression. Ann Rev Psychol 2002; 53: 27-51.

[34] Bushman BJ, Bonacci AM, Pedersen WC, et al. Chewing on it can chew you up: effects of rumination on triggered displaced aggression. J Pers Soc Psychol 2005; 88(6): 969-83.

[35] Murphy CM, O'Farrell TJ, Fals-Stewart W, et al. Correlates of intimate partner violence among male alcoholic patients. J Consult Clin Psychol 2001; 69: 528-40.

[36] Straus MA, Hamby SL, Warren WL. The conflict tactics scales handbook. Los Angeles: Western Psychological Services 2003; p. 146.

[37] Dowling-Guyer S, Johnson ME, Fisher DC. Reliability of drug users' self-reported HIV risk behaviors and validity of self-reported recent drug use. Assessment 1994; 1(4): 383-92.

[38] Needle R, Fisher DG, Weatherby N, et al. The reliability of selfreported HIV risk behaviors of drug users. Psychol Addict Behav 1995; 9(4): 242-50.

[39] Fisher DG, Milroy ME, Reynolds GL, Klahn JA, Wood MM. Reliability of arrest and incarceration questions on the Risk Behavior Assessment. Crime Delinquency 2004; 50(1): 24-31.

[40] Fisher D, Needle R, Weatherby N, Brown B, Booth R, Williams M. Reliability of drug user self-report. in International Conference on AIDS. Berlin, Germany, June 1993.

[41] Buss AH, Perry M. The aggression questionnaire. J Pers Soc Psychol 1992; 63(30): 452-9.

[42] Buss AH, Durkee A. An inventory for assessing different kinds of hostility. J Consult Psychol 1957; 21: 343-9. 
[43] Caprara GV. Indicators of aggression: The dissipation-rumination scale. Pers Individ Dif 1986; 7(6): 763-9.

[44] Novaco RW. The Novaco Scale and Provocation Inventory manual. Los Angeles: Western Psychological Services 2003; p. 58.

[45] Bentler PM. EQS 6 Structural Equations Program Manual. Encino, CA: Multivariate Software, Inc 2006.

[46] Bentler PM, Dudgeon P. Covariance structure analysis: Statistical practice, theory, and directions. Ann Rev Psychol 1996; 47: 56392.
[47] Hu LT, Bentler PM. Cutoff criteria for fit indexes in covariance structure analysis: Conventional criteria versus new alternatives. Struct Equation Model 1999; 6: 1-55.

[48] Kosten TR, Singha AK. Stimulants. In: Textbook of substance abuse treatment. Galanter M, Kleber HD, Eds. Washington, DC: American Psychiatric Press 1999.

Received: March 11, 2009

Revised: September 3, 2009

Accepted: October 5, 2009

(C) Jaffe et al.; Licensee Bentham Open.

This is an open access article licensed under the terms of the Creative Commons Attribution Non-Commercial License (http://creativecommons.org/licenses/by$\mathrm{nc} / 3.0 /$ ) which permits unrestricted, non-commercial use, distribution and reproduction in any medium, provided the work is properly cited. 